\title{
SEGREGAÇÃO DOS RESÍDUOS DE SERVIÇO DE SAÚDE: EDUCAÇÃO AMBIENTAL EM UM HOSPITAL PÚBLICO DO MUNICÍPIO DE ITACOATIARA (AM)
}

\author{
Yana Gomes Inhuma ${ }^{1}$ \\ Gabriel dos Anjos Guimarães ${ }^{2}$ \\ Ricardo Takashi Kuwano ${ }^{3}$ \\ Mariana Medeiros Batista ${ }^{4}$
}

Resumo: Este estudo buscou desenvolver ações de Educação Ambiental com funcionários e gestores de um hospital público do município de Itacoatiara (AM) voltadas à correta segregação dos resíduos. Foram realizadas caracterizações quali-quantitativas dos resíduos, atividades de Educação Ambiental e um levantamento comparativo, antes e após as ações. Foi observada a geração de resíduos comum (70\%), infectantes $(24 \%)$, perfurocortantes (5\%) e químico (1\%). Sugeriu-se ações por meio de palestras e conversas curtas. Foi observado que antes das ações apenas um setor possuía segregação adequada (8\%), após as ações o índice de segregação na fonte aumentou para $77 \%$, mostrando a importância da realização de Educação Ambiental.

Palavras-chave: Gerenciamento de Resíduos; Conscientização Ambiental; Saúde Pública.

Abstract: This study aimed to develop Environmental Education actions with employees and managers of a public hospital in the city of Itacoatiara (AM, Brazil) on the correct way to segregate waste. Quali-quantitative characterizations of the residues, Environmental Education activities and a comparative overview survey were carried out, before and after the actions, on the compliance in the segregation stage. The generation of common (70\%), infectious (24\%), sharps (5\%) and chemical (1\%) waste was observed. Actions were suggested through lectures and short conversations. It was observed that before the actions, only one sector had adequate segregation (8\%), after the actions, the segregation index at source increased to $77 \%$, showing the importance of carrying out Environmental Education.

Keywords: Waste Management; Environmental Awareness; Public Health.

\footnotetext{
1 Universidade Federal do Amazonas. E-mail: yanagomes67@gmail.com, Link para o Lattes: http://lattes.cnpq.br/5171447347263156

${ }^{2}$ Universidade Federal do Amazonas. E-mail: gaguimaraes09@gmail.com, Link para o Lattes: http://lattes.cnpq.br/3766868439579692

${ }^{3}$ Universidade Federal do Amazonas. E-mail: rkuwano@ufam.edu.br,

Link para o Lattes: http://lattes.cnpq.br/7696104513357849

${ }^{4}$ Universidade Federal do Amazonas. E-mail: marianabatista@ufam.edu.br, Link para o Lattes: http://lattes.cnpq.br/9968256068572098
} 


\section{Introdução}

Os Resíduos de Serviço de Saúde (RSS) são considerados aqueles resíduos gerados a partir de quaisquer atividades que estejam relacionadas no âmbito da atenção à saúde humana ou animal e, ainda, aqueles provenientes de serviços de assistência domiciliar (BRASIL, 2018). De acordo com Associação Brasileira de Empresas de Limpeza Pública e Resíduos Especiais (ABRELPE), em 2019, o volume coletado de RSS foi de 252.948 toneladas, relacionando uma coleta per capita de $1,213 \mathrm{~kg} / \mathrm{ano}$. Dentre as alternativas de destinação final destes RSS, destacam-se a incineração $(40,2 \%)$, outros (incluindo lixões, aterros etc., com $36,2 \%)$, autoclave (18,5\%) e microondas (5,1\%) (ABRELPE, 2020).

Dentre os diversos geradores de RSS, os hospitais são considerados os maiores produtores, resultando assim, no aumento da quantidade gerada de resíduos. Diversos são os fatores que contribuem para o aumento da geração de RSS, como o uso intenso de materiais descartáveis, o aumento da complexidade da assistência médica e das inovações tecnológicas, o intenso apelo para o consumo, aliado principalmente com a segregação inadequada dos resíduos (SISINNO; MOREIRA, 2005).

O aumento da quantidade de resíduos contaminados está relacionado diretamente com a deficiência do gerenciamento de RSS. A partir da prática inadequada da segregação na fonte, os resíduos comuns entram em contato com os resíduos infectantes e passam a fazer parte da mesma classe, acarretando no aumento da geração dos resíduos contaminados e dos riscos à saúde dos profissionais que atuam em todas as etapas do manejo (ANDRÉ et al., 2016).

Para Mahler e Moura (2017), o desconhecimento por parte dos profissionais responsáveis pelo gerenciamento de RSS impacta diretamente no processo de capacitação dos demais profissionais de saúde. Sendo assim, segundo a Resolução RDC no 222/2018 (BRASIL, 2018) da Agência Nacional de Vigilância Sanitária (ANVISA), a realização de programas voltados para educação continuada em todos os profissionais atuantes no manejo dos resíduos são instrumentos de suma importância que promovem a adequação do manejo correto dos RSS, bem como a garantia da qualidade de vida da população.

Desta forma, os programas e campanhas de Educação Ambiental são instrumentos salientados pela Lei no 9.795/99 (BRASIL, 1999), a qual institui a Política Nacional de Educação Ambiental. Estes instrumentos de conscientização, proporcionam aos profissionais da esfera pública ou privada e outras, o conhecimento e melhoria das questões ambientais, bem como a qualidade ambiental.

De todo modo, Pinheiro e Silva (2016) destacam que o programa de educação continuada no âmbito dos RSS deverá promover a correta orientação, motivação, conscientização e garantir a adequada informação sobre todos os riscos e procedimentos referente ao manejo dos RSS, para todos os profissionais 
atuantes em estabelecimento de saúde, de forma a contribuir com a redução de resíduos perigosos, por meio da adequação da segregação na fonte, bem como garantir a redução de acidentes ocupacionais oriunda do manejo inadequado dos RSS.

Quando não observada a importância da segregação na fonte dos RSS, diversos são os impactos que estes podem causar ao meio ambiente, bem como acidentes ocupacionais a todos os profissionais atuantes no manejo dos resíduos em hospitais e aos coletores e catadores de resíduos do município. Além dos acidentes, a ausência da segregação, pode favorecer a proliferação de doenças oriundas dos resíduos contaminados, seja por contato direto ou indireto da população, ou através de vetores (MACEDO et al., 2007).

Diante deste contexto, a segregação é caracterizada como uma das principais etapas do gerenciamento de resíduos de serviço de saúde, a partir da qual é possível selecionar a melhor destinação e tratamento dos RSS, bem como reduzir a quantidade gerada e a sustentabilidade do estabelecimento de saúde. A conscientização dos profissionais da área da saúde para a correta segregação dos resíduos, promove e estimula a participação destes, para programas de qualidade ambiental dentro do seu local de trabalho. Assim, o desejado é que os profissionais de todos os níveis e áreas de atuação da unidade hospitalar estejam conscientes da importância da adequada segregação dos RSS, sejam mais atuantes nas etapas operacionais do manejo dos resíduos, encaminhandoos apenas os que realmente necessitem de tratamento específico.

Diante do exposto, esse estudo teve como objetivo desenvolver ações de Educação Ambiental com os funcionários e gestores de um hospital público do município de Itacoatiara/AM voltadas à correta segregação dos resíduos de serviço de saúde, de forma a promover a redução dos resíduos infectantes e contribuir para minimização dos riscos à saúde do trabalhador e ao meio ambiente.

\section{Metodologia}

O hospital, objeto de estudo deste trabalho, possui 114 leitos e 496 colaboradores, dos quais 186 são da Secretaria de Estado de Saúde - SUSAM e 310 são da Secretaria Municipal de Saúde - SEMSA, atuando nas dependências do hospital. A unidade hospitalar é caracterizada como uma unidade polo, prestando serviços não somente para Itacoatiara, mas também para demais municípios vizinhos, como: Itapiranga, Urucará, Urucurituba, Silves e São Sebastião. A Figura 1 apresenta a localização do hospital, objeto deste estudo. 

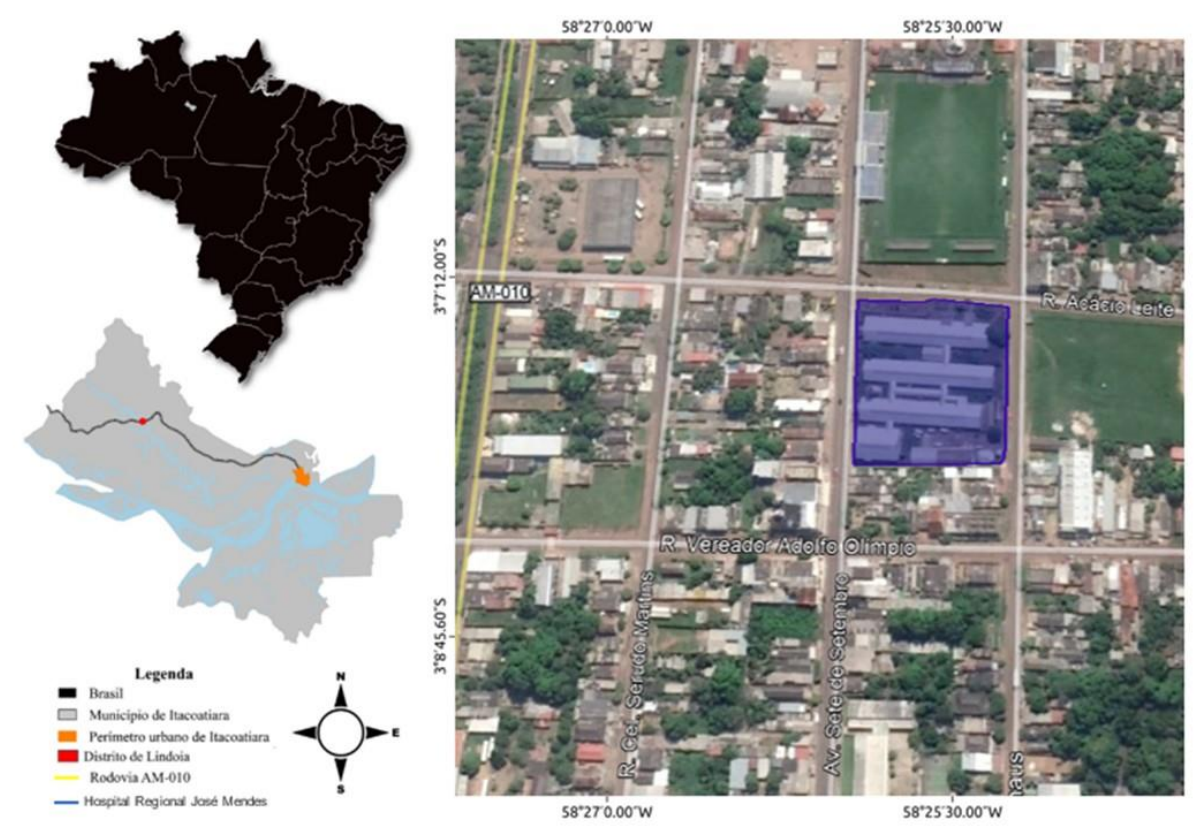

Figura 1: Localização do hospital em estudo, no município de Itacoatiara/AM.

Fonte: Autoria própria.

Para realização deste estudo, foi realizado um levantamento inicial dos setores do hospital, a fim de verificar as fontes geradoras. Em seguida, foi feita a classificação e quantificação dos resíduos através da separação e pesagem, incluindo os infectantes (Grupo A), químicos (Grupo B), comuns (Grupo D) e perfurocortantes (Grupo E). Este procedimento foi realizado diariamente por oito dias consecutivos, o equivalente ao resíduo produzido em 01 semana, exceto para os resíduos químicos, que foram caracterizados durante 15 dias consecutivos, devido à baixa geração. Os resíduos radioativos (Grupo $\mathrm{C}$ ) não foram encontrados em nenhum setor do hospital, devido ele não oferecer esse tipo de serviço.

Os resíduos foram quantificados com o auxílio de uma balança digital e o procedimento de pesagem foi realizado em um local aberto, próximo ao armazenamento externo de resíduo existente na unidade hospitalar para não alterar a rotina do estabelecimento. Posteriormente, os dados foram tabulados e analisados graficamente.

Após esse levantamento inicial, foi aplicado um questionário semiestruturado com os profissionais da unidade hospitalar com intuito de identificar, com base no perfil de cada trabalhador, as melhores ações de Educação Ambiental a serem implementadas nos setores do hospital quanto à segregação dos RSS. Após compreender melhor o nível de conhecimento, necessidades e sugestões dos funcionários e gestores sobre o assunto a ser abordado, foram planejadas e iniciadas as ações de Educação Ambiental voltadas à segregação de RSS na fonte. 
A fim de avaliar a eficiência destas ações, foram efetuadas inspeções internas e a aplicação de um checklist, norteado pela Resolução da diretoria

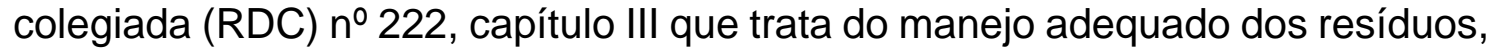
de forma a obter um panorama inicial (antes das ações de Educação Ambiental) e final (após as ações de Educação Ambiental) de conformidade da segregação na fonte em cada setor gerador do hospital.

A realização deste estudo foi desenvolvida no período de setembro de 2019 a fevereiro de 2020, por meio da autorização do gestor do hospital público do município e o acompanhamento direto pelo responsável técnico do gerenciamento de resíduos de serviço de saúde da unidade hospitalar.

\section{Resultados e Discussão}

\section{Classificação e quantificação dos RSS produzidos no hospital}

A classificação dos resíduos de serviço de saúde e as fontes geradoras do hospital estão apresentadas no Quadro 1.

Quadro 1: Tipos de resíduos em cada fonte geradora identificada.

\begin{tabular}{|c|c|c|c|c|}
\hline \multirow{2}{*}{ ORIGEM } & \multicolumn{5}{|c|}{ TIPOS DE RESÍDUOS } \\
\hline Pronto Socorro & $\begin{array}{c}\text { INFETANTE } \\
\text { (Grupo A) }\end{array}$ & $\begin{array}{c}\text { QUímICO } \\
\text { (Grupo B) }\end{array}$ & $\begin{array}{c}\text { COMUM } \\
\text { (Grupo D) }\end{array}$ & $\begin{array}{c}\text { PERFUROCORTANTE } \\
\text { (Grupo E) }\end{array}$ \\
\hline Clínica Médica & $\mathrm{X}$ & $\mathrm{X}$ & $\mathrm{X}$ & $\mathrm{X}$ \\
\hline Administração & & & $\mathrm{X}$ & $\mathrm{X}$ \\
\hline Centro Cirúrgico & $\mathrm{X}$ & $\mathrm{X}$ & $\mathrm{X}$ & $\mathrm{X}$ \\
\hline Maternidade & $\mathrm{X}$ & $\mathrm{X}$ & $\mathrm{X}$ & $\mathrm{X}$ \\
\hline Clínica Pediátrica & $\mathrm{X}$ & $\mathrm{X}$ & $\mathrm{X}$ & $\mathrm{X}$ \\
\hline Banco de Sangue & $\mathrm{X}$ & $\mathrm{X}$ & $\mathrm{X}$ & $\mathrm{X}$ \\
\hline Clínica Cirúrgica & $\mathrm{X}$ & $\mathrm{X}$ & $\mathrm{X}$ & \\
\hline Cozinha/Refeitório & & & $\mathrm{X}$ & \\
\hline Lavanderia & $\mathrm{X}$ & $\mathrm{X}$ & $\mathrm{X}$ & \\
\hline Central de & $\mathrm{X}$ & $\mathrm{X}$ & $\mathrm{X}$ & \\
\hline Abastecimento & & & $\mathrm{X}$ & \\
\hline Farmacêutico & & $\mathrm{X}$ & $\mathrm{X}$ & \\
\hline Manutenção & & & $\mathrm{X}$ & \\
\hline Guarita/Necrotério & $\mathrm{X}$ & & \\
\hline
\end{tabular}

Fonte: Autoria própria.

Observa-se que são gerados todos os tipos de resíduos (Classes A, B, D e E) no hospital e em diferentes setores, exceto os resíduos radioativos, devido à ausência de equipamentos que produzem radionuclídeos no hospital.

Quanto aos resíduos do Grupo B (medicamentos vencidos), estes possuem uma segregação individualizada, oriunda da CAF (Central de Abastecimento Farmacêutico), sendo descartados aqueles que estão fora do prazo de validade. Os demais resíduos do Grupo B, como sobra de medicamentos, álcool, resíduos oriundos de limpeza e laboratorial não obtiveram 
quantificação, devido à ausência da segregação adequada, bem como coletores dos mesmos.

Os resíduos oriundos dos banheiros dos quartos dos pacientes, tais como fraldas descartáveis, absorventes, papel higiênico e outros, bem como aqueles provenientes dos quartos de isolamento, inclusive do banheiro, são incluídos como resíduos comuns, sendo misturados com os demais resíduos comuns provenientes de outros setores da unidade hospitalar. Ocorre a distinção apenas dos resíduos comuns oriundos da cozinha, os quais são segregados em resíduos úmidos (orgânicos) e secos (pratos e copos descartáveis, entre outros) e dos papelões provenientes de todos os setores.

A Figura 2 apresenta a composição gravimétrica dos resíduos de serviço de saúde gerados na unidade hospitalar.

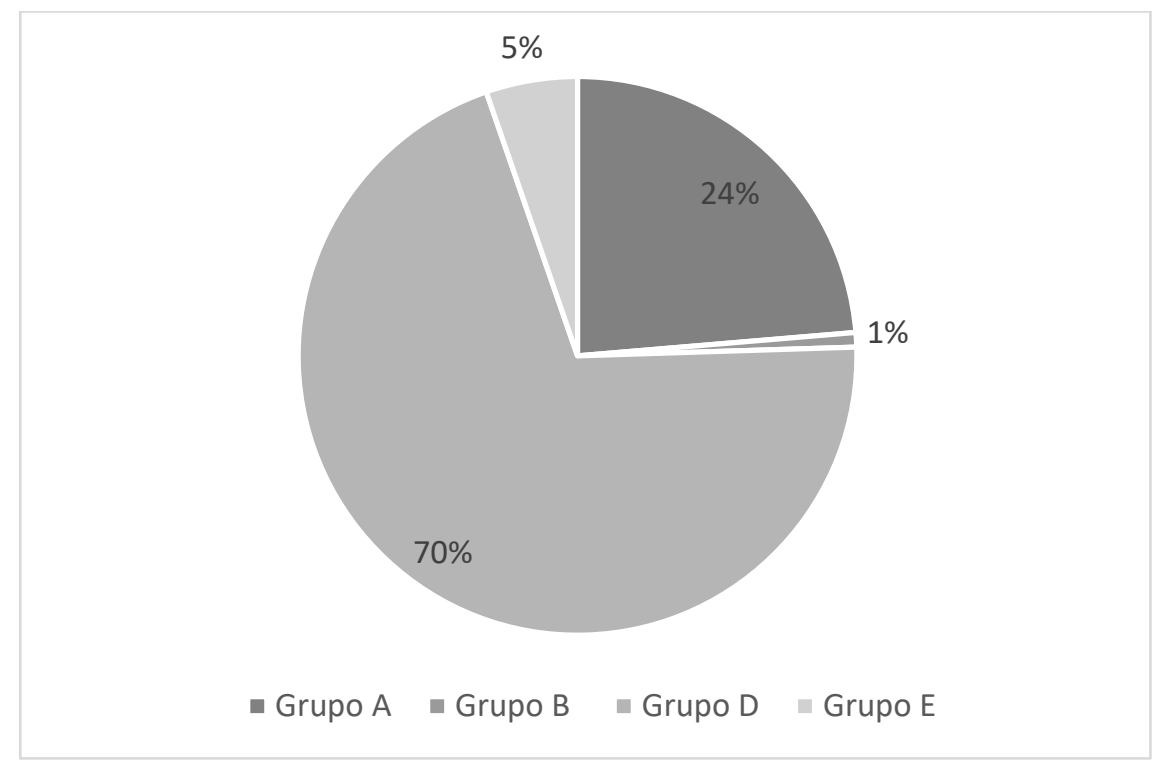

Figura 2: Percentual de geração dos RSS, por classe de resíduo.

Fonte: Autoria própria.

Diante dos dados apresentados na Figura 2, observa-se 0 alto percentual dos resíduos comuns (Classe D) na unidade hospitalar com $70 \%$. Esse elevado valor está relacionado com a alta geração de materiais recicláveis, a exemplo de caixas de papelões, papeis, plásticos moles etc., bem como com a geração dos resíduos orgânicos, oriundos da cozinha e refeição dos pacientes do hospital.

Diante dessa estimativa de geração dos resíduos comuns, a Política Nacional de Resíduos Sólidos (PNRS), Lei no 12.305/2010 (BRASIL, 2010) institui em seu Art. 18, inciso XIV ações voltadas para a redução, reutilização, coleta seletiva e reciclagem dos resíduos, de forma a reduzir a disposição final dos rejeitos, encaminhando-os para um destino sustentável e ambientalmente correto. Deste modo, caso houvesse um programa voltado para a valorização 
destes resíduos por meio da reciclagem e compostagem, como coleta seletiva, poderia beneficiar não apenas o hospital, mas também os catadores locais, que comercializam os materiais recicláveis como fonte de renda, e o meio ambiente, resultando em uma redução na massa de resíduos e rejeitos que seria disposta no Lixão municipal.

Em relação aos resíduos infectantes, estes corresponderam a $24 \%$ dos resíduos gerados, enquanto os perfurocortantes a $5 \%$. Relacionando estes valores aos observados no diagnóstico realizado no ano de 2017, para a elaboração do PGRSS (SOUZA et al., 2017), verificou-se uma diminuição da geração de resíduos biológicos (infectante + perfurocortante) na unidade hospitalar, sendo de $12 \%$ para os resíduos infectantes e $4 \%$ para os resíduos perfurocortantes. Vale destacar que diversos fatores podem influenciar na composição dos RSS, tais como período de amostragem, gestão dos RSS, recursos financeiros e etc., podendo ainda indicar uma melhoria na etapa de segregação.

Por fim, quanto aos resíduos químicos, os mesmos correspondem a $1 \%$ dos resíduos produzidos na unidade hospitalar. Esse baixo percentual é esperado, pois foram quantificados apenas os medicamentos vencidos oriundos da Central de Abastecimento Farmacêutico.

\section{Ações de Educação Ambiental}

Foi perguntado a 39 profissionais da área de enfermagem, medicina $\mathrm{e}$ serviços gerais quais os métodos que seriam fundamentais para promover a adequação da segregação na fonte dos RSS nos setores de trabalho. A Figura 3 apresenta este resultado.

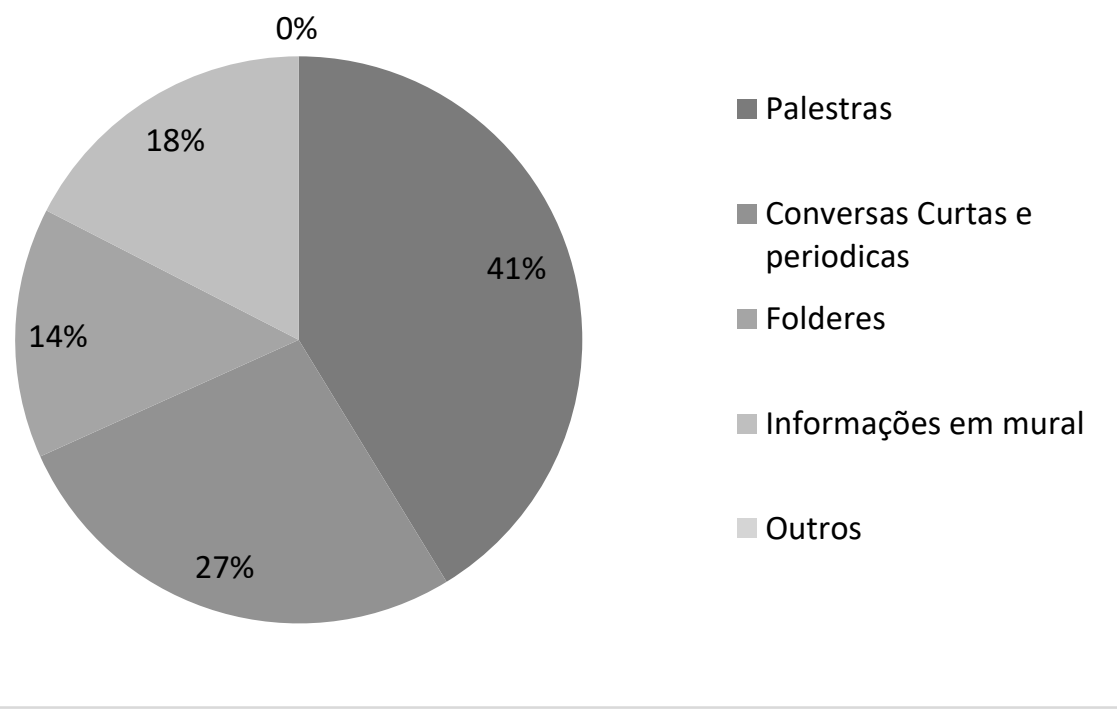

Figura 3: Metodologias para solucionar a segregação na fonte.

Fonte: Autoria própria. 
Com base na Figura 3, foi observado que as principais metodologias que os profissionais da saúde recomendaram para serem implementadas durante as ações de Educação Ambiental foram as palestras (41\%) e as conversas curtas e periódicas $(27 \%)$.

Allevato (2014), em seu estudo sobre "Resíduos de Serviços de Saúde: o conhecimento dos profissionais que atuam no contexto hospitalar", entrevistou 31 profissionais de saúde e salientou que as principais recomendações para facilitar o manejo dos resíduos era a implementação da divulgação de ações, realização de palestras educativas, bem como conversas curtas, identificação dos coletores e a conscientização de cada profissional. Assim como Allevato (2014), os 39 profissionais que participaram do presente estudo salientaram as mesmas contribuições destacadas no estudo do autor supracitado. Estas ações são essenciais para tomada de qualquer decisão que venha contribuir para a eficiência do gerenciamento de resíduos. Promover ações de conscientização ambiental é fundamental e estas devem ser realizadas desde o nível mais baixo ao mais alto da unidade hospitalar, de forma a contribuir com a garantia da qualidade ambiental do hospital e a eficiência do sistema.

Após a obtenção destas recomendações de ações relacionadas à conscientização ambiental, sugeridas por profissionais da área de saúde, foram selecionadas e iniciadas as ações para a garantia da adequação da segregação na fonte.

No período de novembro de 2019 a janeiro de 2020 foram realizadas as ações de Educação Ambiental com o públicos-alvo (funcionários e gestores da unidade hospitalar). Neste período, 73 profissionais da área da saúde participaram deste estudo, o qual envolveu palestras com temas sobre: i) boas práticas do gerenciamento de resíduos de serviço de saúde, direcionada aos funcionários dos diversos setores do hospital; ii) ações civis, penais e administrativas relacionadas aos RSS, direcionada aos gestores; e iii) segurança ocupacional, direcionada à equipe de serviços gerais.

Outra atividade realizada foram as conversas curtas e periódicas que ocorreram dentro dos setores dos hospitais (enfermaria, consultório médico, posto de enfermagem, recepção, refeitório, corredores, farmácias e outros locais), em que foi possível fornecer orientações sobre o descarte correto dos resíduos e apresentar, com auxílio de banner, imagens de situações reais de ausência de segregação dos RSS no hospital que poderiam ocasionar acidentes ocupacionais.

Os programas voltados para conscientização e capacitação da comunidade hospitalar sobre a questão do descarte correto dos resíduos, propiciam também um olhar mais ampliado nas questões ambientais, estimulando assim, a participação dos profissionais nos programas voltados para área ambiental do estabelecimento de saúde (ALLEVATO, 2014). Estas intervenções de Educação Ambiental favorecem a reflexão das práticas atuais do descarte dos resíduos por parte dos profissionais e, consequentemente, estimula a realização do manejo correto e seguro dos RSS (DOI; MOURA, 2011). 
Com a inserção dos profissionais da área de saúde dentro destes programas ambientais, estimula-se a conscientização sobre a importância da segregação adequada dos resíduos gerados e, ainda, a identificação do papel de cada um dentro do gerenciamento de resíduos, contribuindo assim com a sustentabilidade hospitalar.

As palestras de conscientização referente ao gerenciamento de resíduos com a participação dos profissionais de saúde são mais efetivas no setor privado do que no setor público, devido principalmente ao nível de cobrança da prestadora de serviço de saúde com a eficiência do serviço prestado (MOUTTE, 2007). Assim, pôde-se observar no presente estudo a falta de participação de alguns profissionais da área de medicina e enfermagem nas ações para melhoria do gerenciamento de resíduos no estabelecimento de saúde. No presente estudo, foi observado que apenas 73 profissionais do total de 496 participaram das ações, correspondente a um público de $14,7 \%$ de ouvintes do total.

Segundo Berto et al. (2012), os resultados com as capacitações técnicas sobre o gerenciamento de resíduos poderão oferecer resultados positivos após a frequência de participação dos profissionais da área de saúde e as metodologias utilizadas, como visitas de campo, campanhas de conscientização ambiental e palestras com profissionais da área de resíduos. A garantia da qualidade ambiental no estabelecimento de saúde só será eficiente com a participação e colaboração de todos os profissionais que estão na linha de frente da geração de resíduos. Tanto as ações de conscientização e todas as tomadas de decisão para adequação do gerenciamento de resíduos, deverá ser executada por um profissional capacitado, que esteja habilitado para melhorar o sistema de gerenciamento de resíduos de serviço de saúde de determinado estabelecimento.

\section{Avaliação da eficiência das ações de Educação Ambiental}

\section{Avaliação inicial da segregação dos RSS}

Foi realizada a aplicação de um checklist inicial em todos os 13 setores da unidade hospitalar no período de 23 a 30 de setembro de 2019, correspondente a uma semana, norteado pela Resolução da diretoria colegiada (RDC) no 222, capítulo III que trata do manejo adequado dos RSS. Desta forma, a Figura 4 apresenta a relação de conformidade em relação a segregação na fonte dos resíduos nos setores da unidade hospitalar. 


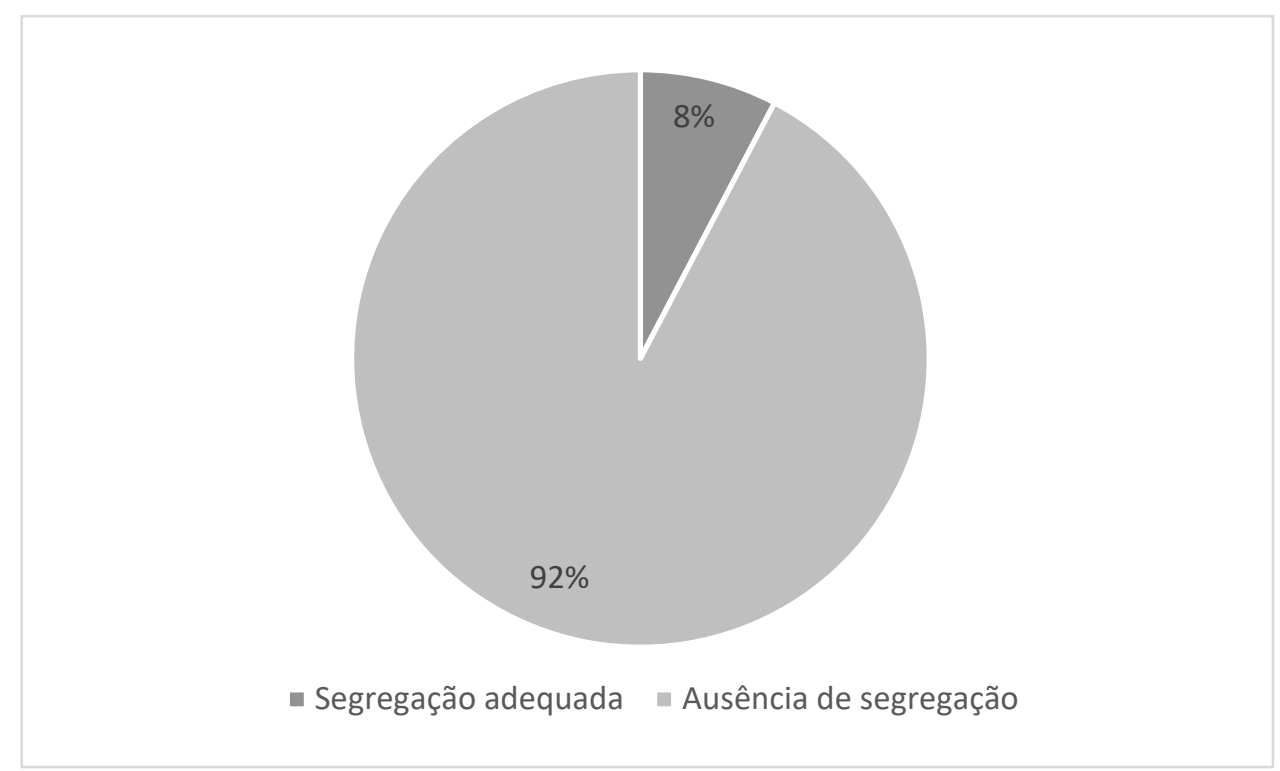

Figura 4: Conformidade na etapa de segregação dos RSS (antes das ações de Educação Ambiental). Fonte: Autoria própria.

Desta forma, com base na Figura 4, observa-se que apenas $8 \%$ dos setores possuíam segregação adequada. Este percentual é representado apenas por um único setor, o setor de administração, que possui apenas a geração da classe de resíduo comum. Entretanto, foi observado que $92 \%$ dos setores não possuem segregação adequada com base nas recomendações técnicas e obrigatórias da RDC № 222/2018.

De acordo com os resultados, em todos os setores da unidade hospitalar, exceto na administração, foram observadas falhas nos procedimentos de segregação do Grupo A. Funcionários, em alguns momentos, acabam descartando os resíduos em qualquer coletor, misturando-os e contaminando os demais, inclusive os resíduos do Grupo D, sendo estes dispostos ao Lixão municipal de Itacoatiara/AM.

Os perfurocortantes (Grupo E), assim como os demais grupos, não possuem segregação adequada. Nas caixas que deveriam ser exclusivamente para a destinação deles, foram encontrados resíduos dos Grupos A, B e D, tais como instrumentos de teste rápido, algodão e demais curativos, sobras de medicamentos, papeis, plástico e outros resíduos dentro do coletor perfurocortante.

Estudo realizado por Vieira (2013) também identificou que resíduos como caixa de remédios, pomada, equipo, papel, gaze, algodão e materiais que deveriam ser destinados em outro recipiente, conforme suas propriedades, estavam sendo descartados em coletores de resíduos perfurocortante (VIEIRA, 2013). Assim, nota-se que, em ambos os estudos, a segregação é o principal problema para o adequado gerenciamento de resíduos de serviço de saúde, podendo ser resolvida com a inserção de práticas de segregação adequada, por 
meio de treinamentos periódicos por profissionais capacitados em relação dos RSS nos estabelecimentos de saúde.

Diversos são os riscos biológicos ocupacionais e contaminação em profissionais oriundos da falta de conhecimento sobre o manejo adequado de RSS, resultando em acidentes com substâncias infecciosa, como HIV, vírus da Hepatite $B$ e Hepatite $C$, oriundo em fluidos e líquidos corporais como o sangue (JANSEN et al., 2015). A partir disto, Valim e Marziale (2011) salientam a preocupação com a exposição destas substâncias infecciosas em instituições de saúde, necessitando assim, de treinamento com os profissionais para otimização das estratégias preventivas. Nota-se que 0 alto índice de segregação inadequada nos setores do hospital, favorecem as ocorrências de acidentes ocupacionais no decorrer do manejo dos RSS, seja na própria geração ou na destinação final.

Por outro lado, esses altos índices de segregação inadequada em uma instituição de saúde promovem danos ambientais, considerando que aumenta a necessidade de construção de aterros sanitários, custos para encaminhamento e destinação final em usinas de incineração e a exploração de matéria prima (ALVES et al., 2012).

Um dos fatores que fazem com que a segregação seja adequada é a presença de dispositivos de acondicionamento em quantidade e qualidade condizentes com o RSS gerado em cada ambiente em que estão inseridos. Moreira e Gunther (2016) consideram dificultosa a segregação do Grupo A quando se tem a falta de recipientes diferenciados e identificação inexistente, o que torna complexo a segregação dos resíduos por parte dos funcionários. No Hospital, foi observado a falta de alguns coletores adequados para os resíduos infectantes, não havendo estoque de coletores para reposição, devido à falta de recursos financeiros destinados para esta finalidade. Assim, a presente unidade hospitalar possui sacos para o acondicionamento dos resíduos do Grupo A de acordo com as recomendações técnicas e obrigatórias da RDC no 222, porém faltam identificações de acordo com as características de cada resíduo afixados em coletores e em locais de fácil visualização em cada setor gerador, sendo este um dos problemas para a ausência da segregação adequada.

\section{Avaliação final da segregação dos RSS}

As inspeções após as ações de Educação Ambiental quanto ao descarte correto de resíduos decorreram nos 13 setores analisados inicialmente, no período de 12 a 19 de fevereiro de 2020.A Figura 5 apresenta graficamente 0 resultado com as ações de Educação Ambiental. 


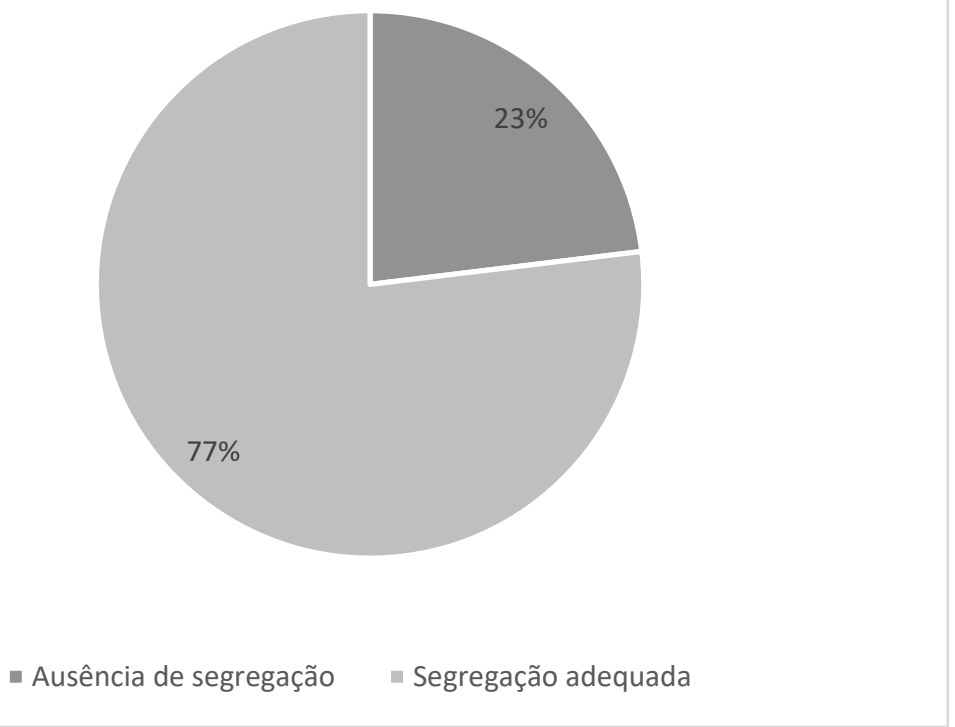

Figura 5: Conformidade na etapa de segregação dos RSS (após as ações de Educação Ambiental). Fonte: Autoria própria.

Conforme a Figura 5, foram verificados que $23 \%$ dos setores ainda não realizavam a segregação de forma adequada dos resíduos mesmo após a inserção das ações de Educação Ambiental. Esse percentual representa os setores considerados de urgência e emergência.

Diante deste contexto, os erros mais comuns observados durante as inspeções após as ações de Educação Ambiental envolveram os descartes dos resíduos dos grupos $\mathrm{A}$ e $\mathrm{D}$, resíduos infectantes e comuns, respectivamente. Foi observado que grande parte dos coletores existentes no interior das salas de medicação, emergência e cirúrgica, que deveriam ser utilizadas exclusivamente para descarte de resíduo comum, acabam sendo utilizadas também para o descarte de resíduos infectantes, devido à falta de atenção na hora do descarte. Nestes locais, também foi identificado que, nos coletores de resíduo infectante, ocorre o descarte inadequado de resíduo comum pelos próprios profissionais da área de saúde. Após a mistura inadequada, todo o resíduo se torna infectante, aumentando assim, o volume de resíduo com grau de contaminação.

Macedo et al. (2007) realizaram um estudo voltado para a segregação de resíduos nos serviços de saúde em um hospital-escola. Este estudo mostrou que dos 30 funcionários participantes, 20 realizaram alguns erros durante a segregação dos RSS. Alguns destes erros foram marcados pelo descarte inadequado de algodão e da gaze não infectados em coletor de resíduo infectante e demais resíduos comuns. Assim como o estudo de Macedo et al. (2007), no presente trabalho, foram observadas falhas de descarte de resíduos infectantes em coletores de resíduo comum, principalmente nas salas de emergência, cirúrgica e postos de enfermagens dos setores com ausência de segregação adequada. 
Observa-se que a gestão integrada dos resíduos deve ser buscada em todos os estabelecimentos de saúde, de forma que venha promover a responsabilidade de cada funcionário na segregação dos resíduos gerados, atribuindo assim, a gestão compartilhada dos resíduos (SILVA, 2012).

Diante deste contexto, para minimizar os transtornos e a melhoria da segurança e segregação adequada, é essencial que a instituição de saúde promova ações de capacitação intensivas para os profissionais que atuam na geração dos RSS nos setores, e fiscalização intensa por profissionais capacitados, de modo a promover a correta prática de segregação dos resíduos na fonte e contribuir para a minimização de acidentes de trabalhos, bem como de impactos ambientais e a valorização dos resíduos com potencial de reciclagem.

Sendo assim, nos $77 \%$ dos setores em que ocorre geração de resíduos contaminados (Figura 5), observou-se a evolução da segregação adequada, o que mostra um maior comprometimento da equipe de saúde em contribuir para a minimização de acidentes ocupacionais e de impactos sobre o meio ambiente. A eficiência das capacitações para garantia do manejo adequado dos RSS também é observada no estudo de Oliveira et al. (2013).

Outro instrumento aliado à Educação Ambiental que favorece uma segregação bem-sucedida é o acondicionamento e identificação dos coletores. Assim, foi possível observar a evolução e contribuição com o descarte correto dos resíduos por meio de acondicionamentos e identificações seguindo as especificações técnicas e obrigatórias da RDC no 222/2018 (BRASIL, 2018). Isso decorre do fato de que atualmente o hospital está com o PGRSS atualizado para 2020 e em estado de implementação das ações para a melhoria da gestão dos RSS por meio de profissionais capacitados.

Diante deste contexto, a solução para o enfrentamento das questões dos RSS vem ser a conscientização, agregada com a educação e a realização de treinamentos e capacitação periódicos de profissionais da área da saúde (GARCIA; RAMOS, 2004). Através do trabalho realizado por Correia e Dias (2003), foi possível observar das ações de Educação Ambiental, por meio das intervenções, palestras e a sensibilização em geral que promoveram a criação de novos hábitos e atitudes oriundas do grupo de estudo, para a minimização da produção de resíduos, bem como a obtenção da segregação adequada. Assim como Correia e Dias (2003), o presente estudo apontou que com a inserção de ações de Educação Ambiental e com a sensibilização dos profissionais em querer melhorar as condições atuais, foi possível promover a correta segregação na fonte dos resíduos. 


\section{Conclusões}

Com base no trabalho realizado, concluiu-se que:

- A quantificação dos RSS apresentou dados relevantes e satisfatórios quando em comparação com o PGRSS de 2017 da unidade hospitalar, de modo que a geração dos resíduos biológicos foi inferior à do presente estudo, enquanto que para os resíduos comuns, houve um aumento considerável.

- As ações de Educação Ambiental foram selecionadas de acordo com as sugestões e o perfil dos profissionais da saúde, sendo as palestras e conversas curtas as principais alternativas para a garantia e eficiência da segregação na fonte dos RSS.

- Foi possível observar que antes das ações de Educação Ambiental sobre a segregação correta dos resíduos, apenas um setor, correspondente a $8 \%$, possuía a segregação na fonte adequada. Com a inserção das ações de Educação Ambiental, este índice alcançou 77\% de setores com segregação adequada.

- É de suma importância que a prestadora de serviço de saúde venha promover a correta atenção aos profissionais responsáveis pelo manejo dos resíduos, de forma que ocorra inspeções internas periódicas, bem como a devida orientação para os profissionais e a capacitação dos mesmos. Investir na gestão dos resíduos de serviço de saúde, promove a sustentabilidade ambiental da unidade hospitalar, de forma que cada vez mais venha diminuir a geração dos resíduos, encaminhar com segurança para a adequada destinação e disposição final e contribuir para o desenvolvimento sustentável da região.

\section{Referências}

ABRELPE. Panorama dos Resíduos Sólidos no Brasil - 2020. Rio de Janeiro, 2020.

ALLEVATO, C. G. Resíduos de Serviços de Saúde: o conhecimento dos profissionais que atuam no contexto hospitalar. 2014. 54f. Dissertação (Mestrado em Enfermagem) - Universidade Federal do Estado do Rio de Janeiro - UNIRIO, Rio de Janeiro. Disponível em: $<$ http://www.unirio.br/ppgenf/dissertacoes/dissertacoes-ppgenf-unirio-ano2014/dissertacao-christiane-garcia-allevato >. Acesso em 30 jul. 2020.

ALVES, S. B. et al. Manejo de resíduos gerados na assistência domiciliar pela Estratégia de Saúde da Família. Rev Bras Enferm [Internet], Brasília, v. 65, n.1, p.128-134. 2012.

ANDRÉ, S. C. S. et al. Geração de Resíduos de Serviços de Saúde em hospitais do município de Ribeirão Preto (SP), Brasil. Eng Sanit Ambient, Rio de Janeiro, v. 21, n.1, p.123-130. 2016. 
BERTO, D. N. et al. Treinamentos sobre resíduos sólidos de serviços de saúde (RSSS) em hospitais de Porto Alegre/RS na percepção de profissionais atuantes. Revista de Gestão em Sistemas de Saúde - RGSS, São Paulo, v. 1, n. 2, p.4162. 2012.

BRASIL. Lei no 9.795, de 27 de abril de 1999. Dispõe sobre a Educação Ambiental, institui a Política Nacional de Educação Ambiental e dá outras providências. Brasília: DOU, 1999. Disponível em: $<$ http://www.planalto.gov.br/ccivil 03/LEIS/L9795.htm>. Acesso em 07 set. 2020.

BRASIL. Lei no 12.305, de 02 de agosto de 2010. Institui a Política Nacional de Resíduos Sólidos, altera a Lei no 9.605, de 12 de fevereiro de 1998; e dá outras providências. Brasília: DOU, 2010. Disponível em: $<$ http://www.planalto.gov.br/ccivil 03/ ato2007-2010/2010/lei//12305.htm>. Acesso em 07 set. 2020.

BRASIL. Resolução RDC no 222, de 28 de março de 2018. Regulamenta as Boas Práticas de Gerenciamento dos Resíduos de Serviços de Saúde e dá outras providências. Brasília, DOU, 2018. Disponível em: $<$ https://www20.anvisa.gov.br/segurancadopaciente/index.php/legislacao $>$.

Acesso em 30 jul. 2020.

CORREIA, J. E; DIAS, S. M. F. Estratégias de Educação Ambiental para o gerenciamento de resíduos sólidos nos laboratórios de análises clínicas e sorologia da UEFS. In: Congresso Brasileiro de Engenharia Sanitária e Ambiental, 22. Anais. Joinville: ABIES, 2003.

DOI, K. M.; MOURA, G. M. S. S. Resíduos sólidos de serviços de saúde: uma fotografia do comprometimento da equipe de enfermagem. Revista Gaúcha de Enfermagem, Porto Alegre, v. 32, n. 2, p.338-344. 2011.

GARCIA, L. P; RAMOS, B. G. Z. Gerenciamento dos resíduos de serviços de saúde: uma questão de biossegurança. Cad. Saúde Pública, Rio de Janeiro, v. 20, n. 3, p.744 -752. 2004.

JANSEN, A. C. et al. Assessment of adherence to post-exposure conducts among health workers: translation and cultural adaptation of an instrument. Texto Contexto Enferm [Internet], Santa Catarina, v. 24, n. 3, p.670-679. 2015.

MACEDO, L. C. et al. Segregação de Resíduos nos Serviços de Saúde: A Educação Ambiental em um Hospital-Escola*. Revista Cogitare Enferm, Curitiba, v. 12, n. 2, p.183-188. 2007.

MOREIRA, A. M. M.; GUNTHER, W. M. R. Gerenciamento de resíduos sólidos em unidades básicas de saúde: aplicação de instrumento facilitador. Rev. Latino-Am. Enfermagem, v. 24. 2016.

MOUTTE, A. et al. Conhecimento do enfermeiro no manejo dos resíduos hospitalares. J. Health Sci. Inst, v. 25, n. 4, p.1-4. 2007. 
OLIVEIRA, C. R. D. R. et al. Gestão de resíduos de serviços de saúde: avaliação dos procedimentos adotados no hospital da cidade de Guaporé-RS. Holos, Natal, v. 2, p.251-60. 2013.

PINHEIRO, L. A.; SILVA, E. R. Estudos sobre resíduos sólidos de serviços de saúde e a Educação Ambiental. Revista Internacional de Ciências, Rio de Janeiro, v.6, n.1, p.1-8. 2016.

SILVA, K. S. Sensibilização e Conscientização dos Profissionais que atuam na sala de recuperação de um Hospital de Porto Alegre, sobre a adequada segregação dos resíduos de saúde. 2012. 36f. Monografia (Especialização em Informação Científica e Tecnológica em Saúde) - centro de educação tecnológica e pesquisa em saúde - escola GHC, Porto Alegre. Disponível em: $<$ https://www.arca.fiocruz.br/bitstream/icict/6821/1/Karina\%20Souza\%20da\%20 Silva\%5b1\%5d.pdf>. Acesso em 30 jul. 2020.

SISINNO, C. L. S.; MOREIRA, J. C. Ecoeficiência: um instrumento para a redução da geração de resíduos e desperdícios em estabelecimentos de saúde. Cadernos de Saúde Pública, Rio de Janeiro, v. 21, n. 6, p. 1893-1900. 2005.

SOUZA, I. G. O. et al. Plano de Gerenciamento de Resíduos de Serviço de Saúde. Hospital Regional José Mendes. Itacoatiara, AM. 2017.

VALIM, M. D.; Marziale, M. H. P. Avaliação da exposição ocupacional a material biológico em serviços de saúde. Texto Contexto Enferm [Internet], Santa Catarina, v.20, p.138-146. 2011.

VIEIRA, C. S. M. Análise do manejo dos resíduos de serviços de saúde em unidade básica de saúde vinculada a uma Instituição de Ensino Superior. 2013. 78f. Monografia (Graduação em Engenharia Ambiental e Sanitária) Universidade Federal de Pelotas. Disponível em: $<$ https://wp.ufpel.edu.br/esa/files/2013/10/TCC-CATIA-VIEIRA.pdf>. Acesso em 30 jul. 2020. 